\title{
MRS Remains Interdisciplinary, Dynamic, and Egalitarian
}

Being President of the Materials Research Society for the past year has been very much like being the thesis advisor of an excellent graduate student. Fortunately, I've been privileged to have that latter opportunity many times. In such experiences, you must somehow get your ideas into a person who is capable of working well without you. You need to nudge gently the tasks already being done well in ways that you hope will make the output even better. And you must use yourself as an additional platform for the fullest expression of the accomplishments. But most of all, you have to figure out how to do no harm, to know how to stay out of the way at the right times and still appear intelligent and productive. I'd like to think I've followed such a strategy for many students over many years; I hope I've done the same for MRS in 1999.

All of the information I've seen for several years, especially in the past year, says that MRS is unquestionably the premier materials society. It is unique in its interdisciplinary, dynamic, and egalitarian postures.

The interdisciplinarity is impossible to miss when you attend a cross section of MRS symposia at any meeting and note how many different disciplines are represented. I've recognized attendees from more than a dozen departments and programs from my own university alone. The author Ivan Amato in his book Stuff: The Materials the World is Made of describes

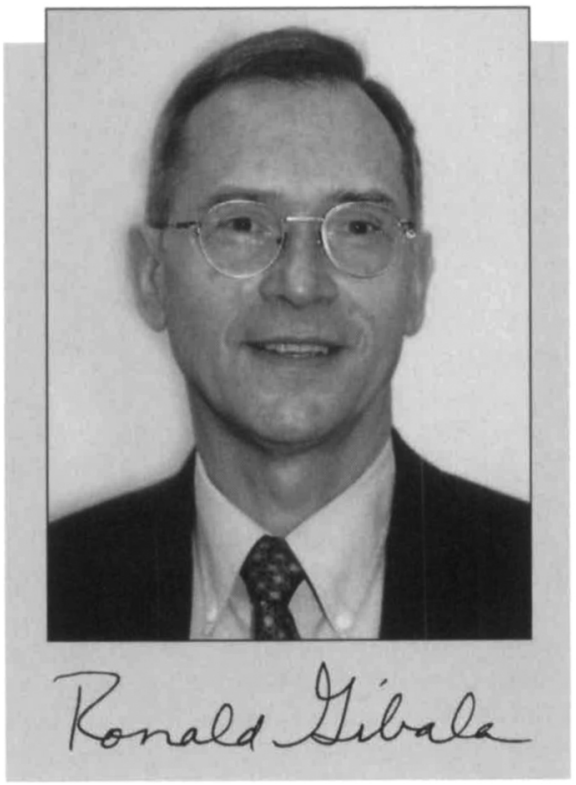

MRS as a Materials Serengeti. Within this metaphor, one can envisage herds of scientists and engineers of all persuasions grazing on the rich intellectual MRS landscape of symposia, exhibits, and special activities. However, unlike those on the Serengeti, the MRS herds roam freely and there is no food chain to speak of. If there are MRS cheetahs feeding off MRS gazelles or wildebeests, the food is in the form of ideas, concepts, models, experimental methods, and other kinds of knowledge.

The dynamicism of MRS is equally obvious. New meeting venues have been tested at both the Spring and Fall Meetings this year. Of more than 40 symposia at the Fall Meeting, a majority are totally new or substantially evolutionary from their predecessor symposia. More symposia are being published electronically, and the Society is examining cost-effective ways to have all symposia available this way in the near future as a membership benefit. President-elect Harry Atwater intends to develop the MRS Web site into the Materials Gateway for all of Materials Science and Engineering.

In my view, the egalitarian nature of MRS is its most intriguing element. There are no special perks for the president. I get to pay the same membership dues, meeting registration fees, and book prices as anyone else. The governing body of MRS-the president, other officers, and councillors-turns over completely within any 3-4-year period. There are no fellows or other special categories of membership, even though healthy debate seems to reemerge every few years. And anyone can propose a symposium for any meeting, but convincing an intentionally independent set of new chairs for each meeting can be another matter.

1999 has been an excellent year of vision, planning, and progress for MRS. I'm very lucky to have had a small part in helping it to happen.

Ron Gibala 1999 President

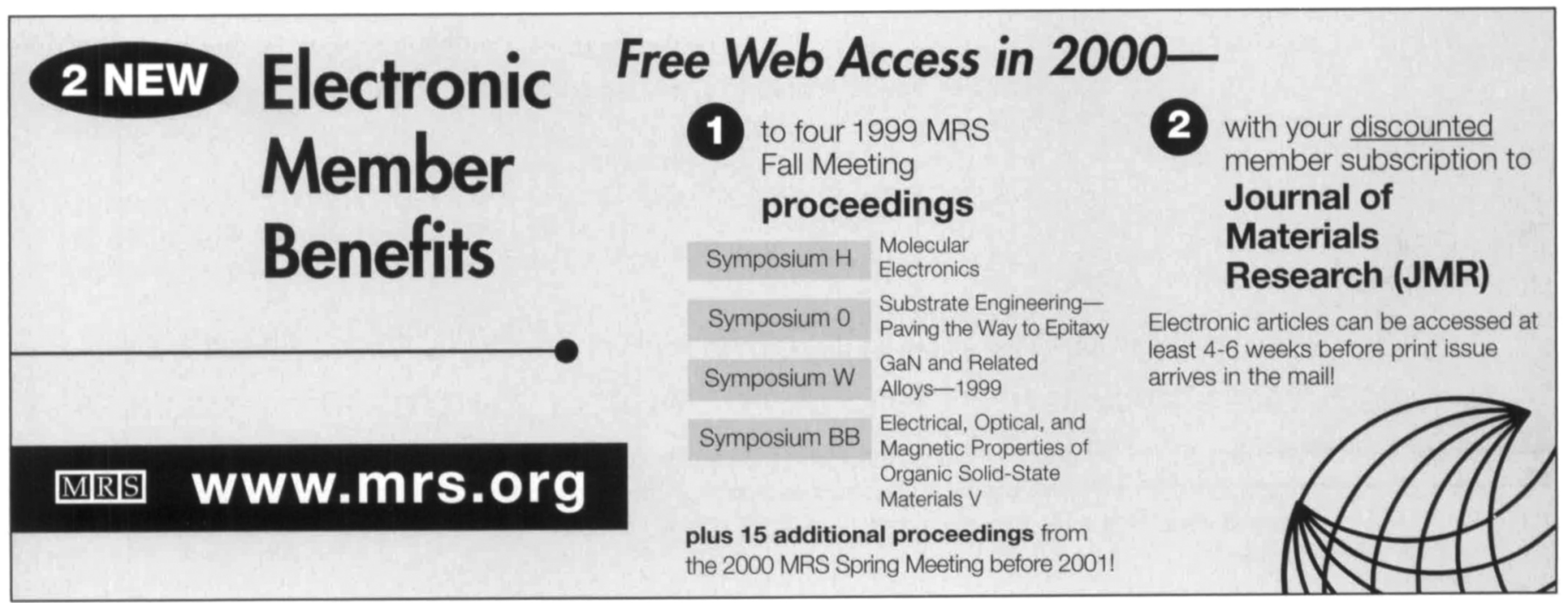

